\title{
Physicochemical Characterization of Coal and its alternative use as a Source of Energy (in case of Yayo Coal Mining Industry)
}

\author{
Bizualem Wakuma ${ }^{1}$ and Busha Assaba ${ }^{2}$ \\ ${ }^{I}$ MSc in Applied Chemistry \\ ${ }^{2} \mathrm{MSc}$ in Analytical Chemistry \\ ${ }^{1,2}$ Mettu University, P. O. Box: 318
}

\begin{abstract}
Coal can be defined as a chemically and physically heterogenous, "combustible", sedimentary rock consisting of both organic and inorganic materials. Organically, coal consists primarily of carbon, hydrogen, and oxygen, with lesser amounts of sulphur and nitrogen. Inorganically, coal consists of a diverse range of ashforming compounds distributed throughout the coal. Two sampling points were selected to undergo the analysis. Three major type of analysis were done: proximate analysis, ultimate analysis and calorific value analysis. Result of laboratory analysis indicates that the calorific value or energy producing capacity of Wittete area ranges from $2894 \mathrm{kcal} / \mathrm{kg}$ to $5885 \mathrm{kcal} / \mathrm{kg}$ which was greater than that of Achibo-Sombo area which ranges from $2314 \mathrm{kcal} / \mathrm{kg}$ to $4847 \mathrm{kcal} / \mathrm{kg}$. Heat value or calorific value determines the energy content of a fuel. It is the property of coal that depends on its chemical composition and moisture content. The most important fuel property is its calorific or heat value Moisture content is a very important property which can greatly affect the burning characteristics of coal. The laboratory result indicates that, the value of moisture content of Wittete area (ranges from $2.6 \%$ to $20.1 \%$ ) is less than that of Achibo-Sombos' area (ranges from $4.28 \%$ to $25.00 \%$ ). From the laboratory result analysis of Wittete and around Yayo area, specifically from percentage of Carbon and calorific value amount Coal rank was determined to be lignite to sub bituminous and medium to high volatile coal.
\end{abstract}

Key words: Physico Chemical Parameters, Coal, Energy, Carbon content

\section{Introduction}

Coal is the world's most abundant and widely distributed fossil fuel. It is a global industry that makes a significant economic contribution to the global economy. Coal is mined commercially in more than 50 countries and used in more than 70. Annual world coal consumption is about 5,800 million tons, of which about $75 \%$ is used for electricity production. This consumption is projected to nearly double by the year 2030 to meet the challenge of sustainable development and a growing demand for energy (A. Mishra, 2009).

Coal is a fossil fuel formed in ecosystems where plant remains were preserved by wood and mud from oxidation and biodegradation. For millions of years, a layer of dead plants at the bottom of the swamps was covered by layers of water and dirt, trapping the energy of the dead plants. The heat and pressure from the top layers helped the plant remains turn into what we call today coal. Coal is a readily combustible black or brownish-black sedimentary rock composed mostly of carbon and hydrocarbons, with small quantities of other elements, notably sulfur. It is a nonrenewable energy source because it takes millions of years to create. The energy in coal comes from the energy stored by plants that lived hundreds of millions of years ago, when the earth was partly covered with swampy forests. It is a sedimentary rock but the harder forms, such as anthracite coal can be regarded as metamorphic rock because of later exposure to elevated temperature and pressure. It is extracted from the ground by mining underground mining or open pit mining /surface mining (K. Rani and S. Kalpana, 2010).

Coal is found in deposits called seams that originated through the accumulation of vegetation that has undergone physical and chemical changes. These changes include decaying of the vegetation, deposition and burying by sedimentation, compaction, and transformation of the plant remains into the organic rock found today. Coals differ throughout the world in the kinds of plant materials deposited (type of coal), in the degree of metamorphism or coalification (rank of coal), and in the range of impurities included (grade of coal).

Objectives of the Study 


\section{General Objective}

The general objective of the study was to analyze/characterize physicochemical parameters of coal and its use as alternative source of energy, (in case of Yayo Woreda, Illubabor Zone, South west Ethiopia)

\section{Specific Objectives}

* To determine the amounts of the physical and chemical elements present in the coal

* To determine the amount thermal energy (calorific value) released from coal per $\mathrm{kg}$

* To identify types of coal present around study area

* To aware the society on the investment opportunity, use of coal as a source of energy in order to decrease deforestation and manufacturing technologies of coal

\section{Statements of the Problem}

The rising energy demand and dependence on coal for power generation management of large volumes of coal fly ash (CFA) produced in thermal power plants is one of the challenging issues to the country along with other environmental aspects. An ecofriendly solution of the problem is the logical necessity of today (K. Rani and S. Kalpana, 2010). Today the use of coal for domestic heat is a very minor market for coal in Ethiopia and only a very small percentage of households use coal as a primary source of energy.

With the growing global demand for alternative sources of energy, such options are thriving in Ethiopia and are juxtaposed to the dominance of coal in Ethiopia's energy mix. The coal- bearing sedimentary basin Block around yayo area is believed to be much greater than what is known today. It is believed that southern part of the basin in Wittete Block continues several tens of $\mathrm{km}$ southwards and therefore there is a good opportunity to develop the coal resource of the Geba basin (T. Kibre. and M. Gashawbez, 1997).

In addition to this, in Ethiopia coal was used only for cooking purpose, but as a result of technology it is also used for different purposes. Coal is burned to produce energy and is used to manufacture steel. It is used as an alternative source for heat generation in lime, aluminum scrap, coke production, cement production, smelting of copper and metallurgical industries.

In addition to this, it is used in various chemical industries and production of nitrogenous fertilizers such as urea (W. Mammo, et. al, 2000).

\section{Significances of the Study}

Now a days with the growing global technology, the demand for alternative sources of energy is a curtail issue to assure this demand. So coal is one of the best alternatives since it has many applications in different industry sectors including household use and agriculture. For instance; Coal is burned to produce energy and is used to manufacture steel. It is used as an alternative source for heat generation in lime, aluminum scrap, coke production, cement production, smelting of copper and metallurgical industries. Even though coal has such advantages, the ash produced in Coal causes all three environmental risks-air, water and ground (land) and spoils the aesthetics of the locality. Therefore environment friendly maintenance is the prime necessity of today. This study will also deal with clean coal technology, which is a collection of technologies being developed to mitigate the environmental impact of coal energy generation (K. Rani and S. Kalpana, 2010 and M. N. Saviourvo, 2012).

Coal is one of crucial energy sources for many countries, which is converted to heat and electrical power by different technologies for our daily life requirements. Therefore, predicting coal quality is an important task and depends on the knowledge of its physical and chemical constitution (A. K. Verma, et.al, 2010). Furthermore, this work could be used as the fundamental consideration for future concerns, for instance: coal trading and its utilizations.

\section{Materials and Methods}

\section{Study Design}

A cross sectional survey on the physicochemical analysis of coal around Yayo Woreda was carried out using different laboratory analysis. Similarly using coal as a source of energy was also carried out.

\section{Sample Collection Techniques and Sample Sites}

The purpose of Collecting and preparing a sample of coal was to provide a test sample which, when analyzed, provide test results representative of the lot sample. This helps ensure an accurate characterization of the coal from which the sample is taken. Proper sampling and sample preparation are critical for accurate analysis (Q. Zhu, 2014).

The sample area was around Yayo Woreda. Within this Woreda three sample sites (Wittete, Achibo and Sombo) was selected depending on the occurrence of coal and previously selected areas as high coal abundance identified as study conducted by Ethiopian mine and energy minister (T. Kibre. and M. Gashawbez, 
1997). Therefore from all selected site, the sample of coal was collected in Plastic bags and care should be taken to avoid contact of the coal with metal during and after collecting sample (V. E. Swanson and C. Huffman, 1976). Immediately after collection, the samples was crushed to approximately $<5 \mathrm{~cm}$ diameter and was well mixed by hand. The method of sample collection at each sampling site was done according to the International and national standards coal analyses guidelines i.e. American Society for Testing and Materials standards for coal analyses (ASTM) (J. G. Speight, 2005).

\section{Coal Analysis Methodologies}

The chemical and physical composition of collected a channel or core sample of coal was analyzed according to International and national standards coal analyses guidelines i.e. American Society for Testing and Materials standards for coal analyses (ASTM). In order to determine the quality of coal, two types of analysis was carried out:

1) Proximity analysis and

2) Ultimate analysis

\section{Proximity Analysis of coal}

The proximity Analysis gives an idea of gross impurities present. This method is used to determine moisture content, volatile matter, ash content and fixed carbon of coal based on American Society for Testing and Materials (ASTM) (J. G. Speight, 2005). It provides important information regarding the suitability of coal for a particular domestic or industrial use.

\section{a) Moisture Content}

Gentle heating of coal at a temperature slightly above the boiling point of water causes a loss of weight from the sample that is defined as moisture. The moisture content of coals ranges from about 5\% to almost $70 \%$. Moisture is an undesirable constituent of coals because it reduces the heating value (water does not burn!) and its weight adds to the transportation costs of coal. The moisture of air-dried, finely powdered coal sample was determined by heating accurately weighed quantity of a sample in a silica crucible at $105-110^{\circ} \mathrm{C}$ for 1 hour in an electric oven. The loss in a weight of sample is found out by the difference in weights.

The percentage of moisture was calculated as

\section{b) Volatile Matter}

$$
\text { percentage of moisture }=\frac{\text { loss in weight of sample }}{\text { weight of air-dried sample }} \times 100
$$

Volatile matter (VM) in coal refers to the thermal decomposition products liberate when coal is heated at high temperature in the absence of air. The percentage of volatile matter is determined by heating accurately weighed air-dried coal sample in a silica crucible covered with lid. The heating is carried out at $925 \pm 5^{\circ} \mathrm{C}$ in a muffle furnace for exactly seven minutes in the absence of air.

$$
\text { Percentage of volatile matter }=\frac{\text { Loss in weight of sample }}{\text { Weight of air }- \text { dried sample }} * 100 \%-\% \text { of moisture }
$$

The volatile matter evolved consists of combustible gases like $\mathrm{CO}, \mathrm{H}_{2}, \mathrm{CH}_{4}$, and other hydrocarbons and incombustible gases like $\mathrm{CO}_{2}$ and $\mathrm{N}_{2}$.

\section{c) Ash content}

Ash is residue obtained after complete combustion of coal and consists of $\mathrm{CaO}, \mathrm{MgO}, \mathrm{SiO}_{2}, \mathrm{Al}_{2} \mathrm{O}_{3}$ and etc. A coal sample after determination of volatile matter was then heated in a muffle furnace at $725-750^{\circ} \mathrm{C}$ without lid for 1 hour. Cooled and weighed. Process of ignition, cooling and weighing was repeated till combustion is complete which is indicated by constant weight of the residue.

$$
\text { Percentage of Ash }=\frac{\text { weight of ash (residue) }}{\text { weight of dried sample }} \times 100
$$

Ash is a non- combustible inorganic matter consists of silica, alumina, iron oxide and small quantities of magnesia as well as lime.

\section{d) Fixed Carbon}

Fixed carbon in coal is the carbon that remains in the coal sample after volatile matter is driven off. The fixed carbon in the coal can be calculated as,

Percentage of fixed carbon $=100-(\%$ age moisture $+\%$ age volatile matter $+\%$ age ash $)$

Quality of coal depends on Percentage of fixed carbon; it should be as high as possible. Fixed carbon varies inversely with volatile matter. More the percentage of fixed carbon, higher is the calorific value. 


\section{Ultimate Analysis of Coal}

Ultimate analysis is the determination of the percentage composition in terms of carbon, hydrogen, sulfur, nitrogen, and ash, and the calculation of the oxygen content the difference.

\section{i. Determination of Carbon and Hydrogen}

Accurately weighed quantity of air- dried coal sample is burnt in stream of oxygen at $1250^{\circ} \mathrm{C}$ in a combustion tube. The combustion tube is a fused-silica tube glazed inside and outside. Its internal diameter is about $18 \mathrm{~mm}$, wall thickness about $2 \mathrm{~mm}$ and total overall length about $112 \mathrm{~cm}$. The carbon and hydrogen content in coal get $\begin{array}{llllll}\text { oxidized } & \mathrm{CO}_{2} & \mathrm{H}_{2} \mathrm{O} & \text { and }\end{array}$ $\mathrm{C}+\mathrm{O}_{2} \rightarrow \mathrm{CO}_{2}$

$$
\mathrm{H}_{2}+1 / 2 \mathrm{O}_{2} \rightarrow \mathrm{H}_{2} \mathrm{O}
$$

The products of combustion are passed through a water absorbing unit containing anhydrous magnesium perchlorate or calcium chloride and then through carbon dioxide absorbing unit containing soda-lime or potassium hydroxide. Increasing in weights of these units is found out which corresponds to weight of $\mathrm{CO}_{2}$ and $\mathrm{H}_{2} \mathrm{O}$ formed due to combustion of carbon and hydrogen respectively or The increase in the weight of $\mathrm{CaCl}_{2} \mathrm{tube}$ represents the weight of water $\left(\mathrm{H}_{2} \mathrm{O}\right)$ formed while increase in the weight of $\mathrm{KOH}$ tube represents the weight of $\mathrm{CO}_{2}$ formed.

$$
\begin{aligned}
& \text { percentage of hydrogen }=\frac{2}{18} \times \frac{\text { Increasing in weight of } \mathrm{H}_{2} \mathrm{O} \text { absorbing unit }}{\text { weight of coal sample }} \times 100 \\
& \text { percentage of carbon }=\frac{12}{44} \times \frac{\text { Increasing in weight of } \mathrm{Co}_{2} \text { absorbing unit }}{\text { weight of coal sample }} \times 100
\end{aligned}
$$

\section{ii. Determination of Nitrogen}

Nitrogen does not contribute towards calorific value. It is determined by Kjeldahl's method. In this method, coal sample is heated with conc. $\mathrm{H}_{2} \mathrm{SO}_{4}$ in the presence of a catalyst like selenium powder or a mixture mercuric sulphate and potassium sulphate. Nitrogen in coal thus is converted to ammonium sulphate and a clear solution is obtained.

$$
2 \mathrm{~N}+6 \mathrm{H}+\mathrm{H}_{2} \mathrm{SO}_{4} \rightarrow\left(\mathrm{NH}_{4}\right)_{2} \mathrm{SO}_{4}
$$

The solution is then treated with $50 \% \mathrm{NaOH}$, to liberate ammonia.

$\left(\mathrm{NH}_{4}\right)_{2} \mathrm{SO}_{4}+2 \mathrm{NaOH} \rightarrow 2 \mathrm{NH}_{3} \uparrow+\mathrm{Na}_{2} \mathrm{SO}_{4}+2 \mathrm{H}_{2} \mathrm{O}$

The liberated ammonia was then distilled over and observed in a known quantity of a standard sulphuric acid. $2 \mathrm{NH}_{3}+\mathrm{H}_{2} \mathrm{SO}_{4} \rightarrow\left(\mathrm{NH}_{4}\right)_{2} \mathrm{SO}_{4}$

Depending up on the amount of liberated ammonia, equivalent amount of $\mathrm{H}_{2} \mathrm{SO}_{4}$ was determined in terms of $\mathrm{N} / 10 \mathrm{NaOH}$ in a back titration $\left(\mathrm{V}_{2} \mathrm{~mL}\right)$. A back titration was carried out to known total quantity of $\mathrm{H}_{2} \mathrm{SO}_{4}$ in terms of $\mathrm{N} / 10 \mathrm{NaOH}$. In blank titration, same quantity of std. $\mathrm{H}_{2} \mathrm{SO}_{4}$ was used to absorb ammonia, was titrated against $\mathrm{N} / 10 \mathrm{NaOH}\left(\mathrm{V}_{1} \mathrm{ml}\right)$. The difference between blank and back titration gives amount of $\mathrm{H}_{2} \mathrm{SO}_{4}$ in terms of $\mathrm{N} / 10 \mathrm{NaOH}$, utilised to absorb ammonia $\left(\mathrm{V}_{1}-\mathrm{V}_{2} \mathrm{ml}\right)$.

$$
2 \mathrm{NaOH}+\mathrm{H}_{2} \mathrm{SO}_{4} \rightarrow \mathrm{Na}_{2} \mathrm{SO}_{4}+2 \mathrm{H}_{2} \mathrm{O}
$$

From this equation, we can write equivalence as

$2 \mathrm{NaOH} \equiv \mathrm{H}_{2} \mathrm{SO}_{4} \equiv 2 \mathrm{NH}_{3} \equiv\left(\mathrm{NH}_{4}\right)_{2} \mathrm{SO}_{4} \equiv 2 \mathrm{~N}$

$\mathrm{NaOH} \equiv \mathrm{N}$, Thus $1000 \mathrm{ml}$ of $1 \mathrm{~N} \mathrm{NaOH}$ was correspond to $14 \mathrm{~g}$ of nitrogen in coal. $1000 \mathrm{ml}$ of $0.1 \mathrm{~N}$ was correspond to $1.4 \mathrm{~g}$ of nitrogen. The percentage nitrogen in coal was calculated by the following equation, where $W$ is weight of coal sample.

\section{iii. Determination of Sulphur}

$$
\text { Percentage of } \mathrm{N}=\frac{(\mathrm{V} 1-\mathrm{V} 2) * \text { Normality of } \mathrm{NaOH} * 1.4}{\mathrm{~W}}
$$

In the estimation of sulphur, washing from bomb calorimeter in finding out calorific value are used. Sulphur percent in coal gets converted to sulphur dioxide which on cooling in calorimeter was absorbed in water to form dilute sulphuric acid. Sulphate was precipitated by treatment with $\mathrm{Ba}\left(\mathrm{NO}_{3}\right)_{2}$ solution precipitated $\mathrm{BaSO}_{4}$ in filtered hot, washed dried and ignited to constant weight.

$$
\begin{aligned}
& \mathrm{SO}_{2}+\mathrm{H}_{2} \mathrm{O} \rightarrow \mathrm{H}_{2} \mathrm{SO}_{3} \\
& 2 \mathrm{H}_{2} \mathrm{SO}_{3}+\mathrm{O}_{2} \rightarrow 2 \mathrm{H}_{2} \mathrm{SO}_{4} \\
& \mathrm{H}_{2} \mathrm{SO}_{4}+\mathrm{Ba}\left(\mathrm{NO}_{3}\right)_{2} \rightarrow \mathrm{BaSO}_{4} \downarrow+2 \mathrm{HNO}_{3}
\end{aligned}
$$

Presence of sulphur is undesirable it produces $\mathrm{SO}_{2}$ and $\mathrm{H}_{2} \mathrm{SO}_{3}$ which is corrosive.

$$
\text { Percent Sulfur }=100 * 0.1374 * \frac{\mathrm{Y}}{\mathrm{X}}
$$

Where, $\mathrm{X}=$ weight of coal sample taken and $\mathrm{Y}=$ Weight of $\mathrm{BaSO}_{4}$ precipitate formed 


\section{iv. Determination of Oxygen}

Higher percentage of oxygen due to mixture constant reduces calorific value. For a good quality of coal, it should have very low oxygen content

Percentage of oxygen was calculated as follows:

Percentage of oxygen $=100-[$ Percentage moisture + Percentage $\mathrm{H}+$ Percentage $\mathrm{N}+$ Percentage $\mathrm{S}+$ Percentage Ash]

\section{v. Determination of Chlorine Content}

There are different ASTM standard methods of determining chlorine in coal: Total Chlorine in Coal can was determined by the Oxygen Bomb Combustion/Ion Selective Electrode Method.

A given gram of the analysis sample of coal was placed in a crucible inside an oxygen bomb. An ammonium carbonate solution was added to the bomb to trap the chloride-containing species produced in the combustion. After charging with oxygen to atmospheres, the bomb was fired and allowed to stand in the calorimeter water for at least $10 \mathrm{~min}$. The pressure on the bomb was then released slowly, the bomb was disassembled, and all parts of the bomb interior were washed with hot water. The washings were collected in a beaker and acidified with nitric acid. The amount of chloride in the solution was then determined by a potentiometric titration with silver nitrate solution (John T. Riley, 2007) and (W.R.Hibbard, 1967)

\section{vi. Determination of Carbon Dioxide Content}

The determination of the carbon dioxide content of coal was made by decomposing, in a closed system, a weighed sample of coal with hydrochloric acid, which liberates the carbon dioxide. This was absorbed in a $\mathrm{CO}_{2}$ absorbent, such as $\mathrm{NaOH}$ or $\mathrm{KOH}$ on an inert carrier. The increase in mass of the absorbent was a measure of the $\mathrm{CO}_{2}$ released by the coal sample, which could be used to calculate the amount of mineral carbonates in the coal (John T. Riley, 2007). Small amounts of mineral carbonates occur in many coals and comparatively large amounts in some coals. The determination of carbon dioxide was required in estimating the mineral-matter content of higher-carbonate coals for classification purposes. Carbon dioxide was determined by boiling the coal with dilute hydrochloric acid and absorbing the liberated carbon dioxide in suitable absorbent (W.R.Hibbard, 1967)

\section{vii. Determination of Calorific Value of Coal}

Gross Calorific Valve (Specific Energy) - Calculated from the measured amount of heat released when the coal was burnt in excess oxygen in a bomb calorimeter under standard conditions i.e. it was determined by bomb calorimeter (John T. Riley, 2007). The bomb calorimeter consists of a strong stainless steel vessel, called bomb, capable of withstanding high pressures. The bomb was provided with a lid which could be screwed firmly on the bomb. The lid in turn was providing with two electrodes and an oxygen inlet valve. One of the electrodes was provided with a ring to accommodate the silica crucible. The bomb was placed in a copper calorimeter having a known weight of water. The copper calorimeter, in turn, was surrounded by an air jacket and a water jacket to prevent loss of heat due to radiation. The calorimeter was provided with an electrical stirrer for stirring water and a Beckmann"s thermometer (O.W.Rees, 2012).

\section{Result and Discussion}

The Physico-chemical parameters analyzed were categorized into two major parameter categories.

$>$ Proximity analysis and

$>$ Ultimate analysis

Sample from all selected areas Geba Basin (Wittete and around Yayo) and Achibo-Sombo were collected and all parameters were analyzed according to their procedure. In addition to this, during the analysis triplicate values was recorded and the average value was taken according to the following table.

Table 1: Laboratory result for Wittete and around Yayo area

\begin{tabular}{|l|l|l|l|l|l|}
\hline No. & Parameters & Trial-1 & Trial-2 & Trial-3 & Mean value \\
\hline 1. & Ash content & $3.31 \%$ & $23.4 \%$ & $30.37 \%$ & $19.23 \%$ \\
\hline 2. & Calorific value & $2894 \mathrm{kcal} / \mathrm{kg}$ & $4465 \mathrm{kcal} / \mathrm{kg}$ & $5985 \mathrm{kcal} / \mathrm{kg}$ & $4448 \mathrm{kcal} / \mathrm{kg}$ \\
\hline 3. & Moisture content & $2.6 \%$ & $10.3 \%$ & $20.1 \%$ & $11.00 \%$ \\
\hline 4. & Volatile matter & $27.3 \%$ & $28.3 \%$ & $36.6 \%$ & $30.74 \%$ \\
\hline 5. & Fixed carbon & $39.3 \%$ & $47.6 \%$ & $48.9 \%$ & $45.27 \%$ \\
\hline 6. & Sulphur (total)content & $0.560 \%$ & $0.865 \%$ & $0.950 \%$ & $0.792 \%$ \\
\hline 7. & Percentage of Hydrogen & $3.00 \%$ & $3.02 \%$ & $4.10 \%$ & $3.73 \%$ \\
\hline 8. & Percentage of Oxygen & $8.82 \%$ & $8.25 \%$ & $9.12 \%$ & $8.73 \%$ \\
\hline 9. & Percentage of Nitrogen & $1.35 \%$ & $1.36 \%$ & $1.45 \%$ & $1.39 \%$ \\
\hline 10. & Carbon dioxide (lb/ton) & 1.32 & 1.13 & 2.31 & 1.59 \\
\hline 11. & Chlorine & $1.58 \%$ & $0.98 \%$ & $2.42 \%$ & \\
\hline
\end{tabular}


Table 2: Laboratory result for Yayo (Achibo-Sombo) area

\begin{tabular}{|l|l|l|l|l|l|}
\hline No. & Parameters & Trial-1 & Trial-2 & Trial-3 & Mean value \\
\hline 1. & Ash content & $5.310 \%$ & $23.7 \%$ & $33.77 \%$ & $20.92 \%$ \\
\hline 2. & Calorific value & $2314 \mathrm{kcal} / \mathrm{kg}$ & $2534 \mathrm{kcal} / \mathrm{kg}$ & $4847 \mathrm{kcal} / \mathrm{kg}$ & $3131.67 \mathrm{kcal} / \mathrm{kg}$ \\
\hline 3. & Moisture content & $4.28 \%$ & $8.50 \%$ & $25.00 \%$ & $12.59 \%$ \\
\hline 4. & Volatile matter & $27.3 \%$ & $28.3 \%$ & $36.6 \%$ & $30.73 \%$ \\
\hline 5. & Fixed carbon & $39.3 \%$ & $47.6 \%$ & $48.9 \%$ & $46.27 \%$ \\
\hline 6. & Sulphur content & $0.56 \%$ & $0.865 \%$ & $0.950 \%$ & $0.79 \%$ \\
\hline 7. & Percentage of Hydrogen & $3.00 \%$ & $3.02 \%$ & $4.10 \%$ & $3.37 \%$ \\
\hline 8. & Percentage of Oxygen & $8.82 \%$ & $8.25 \%$ & $9.12 \%$ & $8.73 \%$ \\
\hline 9. & Percentage of Nitrogen & $1.35 \%$ & $1.36 \%$ & $1.45 \%$ & $1.39 \%$ \\
\hline 10. & Carbon dioxide (lb/ton) & 1.32 & 1.13 & 2.31 & 1.59 \\
\hline 11. & Chlorine $(\%)$ & 1.58 & 0.98 & 2.42 & 1.66 \\
\hline
\end{tabular}

\section{Discussion}

From laboratory analysis result, for each sampling points trial analysis was done. The average result was discussed. Accordingly, these results were discussed and compared with different scholars under this title and also was compared with the standard for each coal type. Major physicochemical parameters were analyzed and the analyzed parameters have direct relation with the energy giving of coal.

According to Yang et al. (2005) moisture content is a very important property which can greatly affect the burning characteristics of coal. Aina et al. (2009) also reported that, moisture content is one of the main parameters determining coal quality as lower moisture content of coal implies higher calorific value. Moisture content affects both the internal temperature history within the solid, due to endothermic evaporation, and the total energy that is needed to bring the solid up to the pyrolytic temperature. The moisture content of analyzed coal from Wittete area was recorded as having the average value of $11.00 \%$. The minimum value and maximum value recorded was $2.66 \%$ and $20.1 \%$ respectively. This result was in lined with China National Complete Plant Import and Export Corporation LTD 2007(COMPLANT, 2007), and also in lined with Gebreyohannes, 2001.

Volatile matter represents the components of carbon, hydrogen and oxygen present in the coal that when heated turn to vapour, usually a mixture of short and long chain hydrocarbons. (Chaney, 2010) Volatile content has been shown to influence the thermal behavior of solid fuels but this is also influenced by the structure and bonding within the fuel. The moisture content of analyzed coal from Wittete area was recorded as having the average value of $11.00 \%$.

According to Kim et al. (2001) ash has a significant influence on the heat transfer to the surface of the fuel, as well as the diffusion of oxygen to the fuel surface during char combustion. The values of volatile matter and ash content observed in this study are good and acceptable.

Heat value or calorific value determines the energy content of a fuel. It is the property of coal that depends on its chemical composition and moisture content. The most important fuel property is its calorific or heat value (Aina et al., 2009).

From the laboratory result analysis of Wittete and around Yayo area, specifically from percentage of Carbon and calorific value amount Coal rank was determined to be lignite to sub bituminous and medium to high volatile coal (table above). These results were in lined with Gebreyohannes' result done in 2001.

According to Zarihun et al, 1998, the subsurface exploration carried out at Yayo (Achibo-Sombo) area has confirmed the presence of four major lithologic units. According to their position in the stratigraphic sequence these units are listed from the oldest to the youngest as follows: Basement complex, Lower basalt, Sedimentary rock unit, Upper basalt. The upper basalt is the youngest rock unit in the study area. It mainly comprises fragmented, jointed and strongly fractured aphanitic basalt. The intensity of weathering is very strong both in the vertical and horizontal extensions and has changed the rock into slightly to completely weathered materials. From megascopic observation the presence of limonite, carbonate, silica and some chlorite coatings along fractures and joints were noted.

Distinct layers of pyroclastic rocks and tuffaceous sediments interbeded with the upper basalt are locally encountered in the study area. The laboratory result analysis indicates that the coals have medium to high volatile matter, medium to high ash content, relatively low to medium sulfur content and fixed carbon content. The majority of the coal samples falls within lignite B to sub bituminous C ranks and are non-agglomerating. Comparatively, the calorific value of coal per kg from Wittete and around Yayo area is greater than that of Yayo (Achibo-Sombo) area.

Generally, the findings of this study have shown that, energy/fuel produced from coal would make good fuel. The Physico-chemical characteristics of the coal assessed in this study showed that the energy /produced manufactured from the coal has low moisture content, high calorific value and low ash content. 


\section{Recommendation}

The following recommendation can be given to the concerned body:

$\checkmark \quad$ There is future and market potential for coal in this area since the survey revealed a positive attitude for the use of coal by the respondents.

$\checkmark$ High calorific value was recorded at Wittete area this indicates high energy producing coal can be mined and special care should be taken during mining by the concerned body

$\checkmark \quad$ During mining process special care should be given for the employees around the area and also care should be taken regarding to the pollution of environment

$\checkmark$ This research result can be used as an input for further analysis specially regarding to special elements like hazardous radioactive metals.

\section{References}

[1] MISHRA, (2009), Assessment of coal quality of some Indian coals, MSC Thesis, National Institute of Technology, Rourkela

[2] K. Verma, T. N. Singh, M. Monjezi, (2010), Intelligent prediction of heating value of coal, S. D. Limaye / Iranian Journal of Earth Sciences, vol.2, pp (32-38)

[3] China National Complete Plant Import and Export Corporation LTD, (2007).Geological Report (Final) on Detailed Exploration of Wittete Minefield. Addis Abeba.

[4] Tigist W, (2007), Coal Exploration Result in Ethiopia, Hydro carbon Exploration Team, GSE (Unpublished report).EIGS, Addis Abeba.

[5] Gebre Yohannes H. (2001), Geological report on coal deposit extension investigation around Wittete and Yayo blocks, Vol. 1\&2 (Unpublished report). EIGS, Addis Abeba.

[6] Wondafrash Mammo, Sentayehu Zewdie and Geremew Negassa (2000), Geological Survey of Ethiopia (GSE), Addis Ababa

[7] M. Naveen Saviourvol (2012), Environmental Impact of Soil and Sand Mining International Journal of Science, Environment and Technology, 1, No 3, $125-134$

[8] John T. Riley, (2007), Routine Coal and Coke Analysis: Collection, Interpretation, and Use of Analytical Data, ASTM International, West Conshohocke.

[9] Krishna Rani and 2Kalpana S, (2010), Utilization in agricultural and related fields; a better alternative for ecofriendly maintenance of Coal Fly Ash, Journal of Chemical and Pharmaceutical Research, 2(5):365-372

[10] K. Rani, S. Kalpana (2010), Utilization in agricultural and related fields; a better alternative for ecofriendly maintenance of Coal Fly Ash, Journal of Chemical and Pharmaceutical Research, vol.2(5) pp(365-372)

[11] O.W.Rees (2012), Chemistry, Uses, and Limitations of Coal Analyses, Illinois State Geological Survey, Urbana, Illinois.

[12] Kibre T. and Gashawbeza M. (1997), Preliminary geological report of Geba Basin, (Yayu area), Illubabor (Unpublished report).EIGS, Addis Abeba.

[13] Q. Zhu, (2014), Coal sampling and analysis standards, IEA Clean Coal Centre, Park House 14, Northfields , London, United Kingdom.

[14] Wolela A., (1985), Report on the drilling results of Jiren coal occurrences (Unpublished report).EIGS, Addis Abeba

[15] E. Swanson, C. Huffman,(1976), Guidelines for Sample Collecting and Analytical Methods Used in the U.S. Geological Survey for Determining Chemical Composition of Coal, geological Survey Circular 735.

[16] J. G. Speight, (2005), Handbook of coal analysis, vol.166, John Wiley \& Sons, Inc., Canada

[17] Kim, H. J., Lu, G. Q., Naruse, I., Yuan, J. and Ohtake, K. (2001). Modeling combustion characteristics of biocoalbriquettes. Journal of Energy Resources Technology, vol. 123, pp.

[18] Chaney, J. (2010). Combustion characteristics of biomass briquettes. Unpublished PhD studies. W.R.Hibbard, (1967), method of analyzing and testing coal and coke, U.S. Washington.

[19] Yang, Y. B., Ryu, C., Khor, A., Yates,N. E., Sharifi, V. N. and Swithenbank, J. (2005). Effect of fuel properties on biomass combustion. part ii. Modeling approach-identification of controlling factors, Fuel, vol. 84, pp. 2116-2130

[20] Aina, O. M., Adetogun, A. C. And Iyiola, K. A. (2009). Heat Energy from Value-Added Sawdust Briquettes of Albizia Zygia. Ethiopian Journal of Environmental Studies and Management Vol.2 No.1. pp 42-49.

[21] EIA, International Energy Annual 2001 (U.S. Department of Energy, Energy Information Administration, Washington, D.C., March 2003), pp. 114-115.

[22] World Bank Group, Coal Mining and Production, Pollution Prevention, and Abatement Handbook, www.naturalresources.org.minerals/CD/docs/twb/ PPAH/52.coal.pdf, pp. 282-285 (accessed July 1998).

[23] Sengupta, M., Environmental Impacts of Mining: Monitoring, Restoration, and Control (Lewis Publishers, Boca Raton, FL, 1993). 